\title{
DESIGN OF LEARNING ANALYTICS DASHBOARD SUPPORTING METACOGNITION
}

\author{
Li Chen ${ }^{1}$, Min Lu², Yoshiko Goda ${ }^{3}$ and Masanori Yamada ${ }^{2}$ \\ ${ }^{1}$ Graduate School of Human-Environment Studies, Kyushu University \\ 744, Motooka, Nishi-ku, Fukuoka 819-0395, Japan \\ ${ }^{2}$ Faculty of Arts and Science, Kyushu University \\ 744, Motooka, Nishi-ku, Fukuoka 819-0395, Japan \\ ${ }^{3}$ Research Center for Instructional Systems, Kumamoto University \\ 2-39-1, Kurokami, Chuo-ku, Kumamoto, 8600862 Japan
}

\begin{abstract}
Metacognition is an aspect in self-regulated learning and is necessary to achieve such learning in an effective and efficient manner. However, it is not always easy and accurate for learners to monitor or assess their own metacognition. In this study, we designed a learning analytics dashboard to improve self-regulated learning in online environments through the collection and analysis of learning log data. There are two separate dashboards used in our system: a knowledge monitoring dashboard and a strategy use dashboard. The knowledge monitoring dashboard is designed to support the knowledge monitoring skills of learners, allowing them to monitor their prior knowledge, whereas the strategy use dashboard is designed to help learners develop metacognitive skills of planning, monitoring, and regulation.
\end{abstract}

\section{KEYWORDS}

Metacognition, Self-Regulated Learning, Dashboard, Learning Analytics

\section{INTRODUCTION}

Self-regulated learning (SRL) is considered an effective way to achieve academic goals such as test grades and academic skills in school, or even the capacity to self-instruct in the future (Zimmerman, 2002). SRL is considered to be a self-directive process, through which SRL learners transform their mental abilities or intelligences into academic skills (Zimmerman, 1998). SRL is closely linked to the concept of self-generated thoughts, feelings, and behaviors, particular in terms of metacognition and motivation (Tobias and Everson, 2009; Zimmerman, 1998; Zimmerman, 2002). Considering the metacognition in SRL, it is necessary to allow learners to make sense of their own learning process and take responsibility for their own learning.

As information and communication technologies advance, various types of data can be collected, not only test scores and psychometric data, but also learning logs to allow learning behaviors to be analyzed through a learning analytics (LA) approach. This new approach provides a new direction for recording and monitoring learning and for supporting learners in developing their metacognitive skills through SRL.

This paper aims to design a learning analytics dashboard to support the metacognition skills of learners by visualizing their log data during the SRL process.

\section{THEORETICAL BACKGROUND}

\subsection{Metacognition and SRL}

SRL strategies are defined as "actions and processes directed at acquiring information or skill that involve agency, purpose, and instrumentality perceptions by learners" (Zimmerman, 1989). Self-regulation is an 
important construct of learning that includes both metacognition and motivation dimensions (Tobias and Everson, 2009).

Metacognition, which refers to the ability to set goals or plans, monitor and evaluate one's own learning (Tobias and Everson, 2002), is one aspect of SRL and is necessary in regulating learning in an effective and efficient manner (Tobias and Everson, 2009). Many models of metacognitive strategies concerning SRL include three general scales, namely, planning, monitoring, and regulating (Hofer et al., 1998; Pintrich et al., 1993; Pintrich, 1999).

Planning activities contain the usage plan of several cognitive strategies, such as setting goals and criteria or standards for evaluation, clarifying the aim of the learning activities, and conducting task analyses of problems (Belfiore and Hornyak, 1998; Hofer et al., 1998; Zimmerman, 1989). By planning activities, learners are expected to develop a cognitive strategy utilization, activate their relevant prior knowledge and experience, and improve their organization and understanding of the learning content (Hofer et al., 1998).

Monitoring activities include tracking one's attention during the learning processes, checking the degree of understanding, and use of learning or examination strategies (Hofer et al., 1998; Lan, 1998) by observing or recording one's own learning behaviors or performance (Belfiore and Hornyak, 1998; Zimmerman, 1989). Monitoring one's own learning behaviors and processes is an important aspect in SRL because it helps learners to be aware of their weaknesses or deficiencies in their learning processes and regulates their learning strategies or academic behaviors during the next phase (Hofer et al., 1998; Winne and Stockley, 1998).

Regulation strategies are related to and based upon monitoring strategies, and they aim at improving the learning behaviors of learners and repairing deficits in their comprehension (Hofer et al., 1998). For example, learners focus on one part of a text, summarize what they have read, and reread the texts based on their comprehension, adjusting their learning/reading pace according to their learning ability, or choosing course-related materials (Hofer et al., 1998; Thiede et al., 2009).

However, it has been shown that metacognitive skills are required to monitor one's own prior knowledge for effective and efficient learning (Tobias and Everson, 2002, 2009). The lack of an ability to distinguish correctly what learners know or have learned, from what they do not know or need to learn, will lead to a failure to engage in more advanced metacognition strategies (Tobias and Everson, 2009; Yen et al., 2018). This is because metacognition strategies are highly ordered processes used to monitor and coordinate basic or complex cognitive processes. However, learners with low or underdeveloped knowledge monitoring skills are considered to be inefficient at reading the learning materials, leading to a failure to apply a reasonable time allocation and sequence management. Thus, Tobias and Everson (2009) emphasized the importance of knowledge monitoring (KM), which is the metacognitive ability to monitor one's prior knowledge, and placed monitoring knowledge at the bottom of all metacognitive phases, indicating that it is the fundamental component of metacognition.

Therefore, in our study, a dashboard for supporting the metacognition of learners was designed based on the dimensions of knowledge monitoring, planning, monitoring, and regulation.

\subsection{Metacognition and Learning Analytics}

Although metacognition is an important and effective way for learners to monitor and regulate other cognitive strategies, metacognition measurements are facing considerable challenges. When observing the performance of learners, or assessing their metacognition through self-reported inventories, the validity of the inferences of these evidence-based approaches, as well as the accuracy and candor of a self-assessment, are problems and issues to be overcome (Tobias and Everson, 2009; Winne and Nesbit, 2009). For example, learners cannot observe or remember all events or their learning behaviors during their learning activities. In addition, their perception will be influenced by their previous experience, the pace of events, biases, their memory, and other factors.

Concerning these issues in measuring metacognition, information and communication technology (ICT) has shown significant potential in collecting learning log data. As ICT advances, the types of log data and the methods of data collection vary. For example, the interaction between or across learners, or between learners and computers, can be collected to show the software or system features the learner uses (Tobias and Everson, 2009). In addition, the system operations during the entire learning process can also be collected, such as copying or highlighting texts, or adding annotations, to present the learning behaviors of learners (Tobias and 
Everson, 2009; Yamada et al., 2017; Yen et al., 2018).

In Yamada et al.'s (2017) study, the correlations between SRL awareness, learning performance, and behaviors, such as the duration of the slide pages read, the adding of markers, and annotations, were analyzed. As the results indicate, the slide pages that the learners read for a certain duration (from 240 to 299 s) have positive effect on their annotation utilization and learning performance improvement.

\subsection{Visualization}

Yen et al. (2018b) pointed out that visualization is useful for learners to be aware of what they have been doing and what they should do by making such information salient for them. For example, in online inquiry activities, the visualization of driving questions, a set of goals, or the structure and sequence and associations of tasks, could help learners conduct such activities more smoothly, such as planning, monitoring, and evaluating during SRL (Manlove et al., 2006; Zhang and Quintana, 2012).

However, such visualization tools have been used in domain-specific systems. Considering the utilization of visualization to support the general skills and metacognition of learners, visualization tools should be applied in domain-general systems.

Learning analytics has many advantages including the continuous and automatic collection of the learners' data in ubiquitous learning environments, which are not interfered with by the learners' engagement or intervention of external instructors (Yamada et al., 2016; Yin et al, 2015). Teachers can understand learner's learning behaviors out of class and informal learning settings (Shimada et al, 2015). Integrating these advantages into a dashboard, learning analytics can be provided through a visual display of the data information, informing the learners regarding undetectable patterns of their progress and behaviors (Teasley, 2017) by collecting and analyzing the data generated from online learning platforms, primarily a learning management system (LMS). As Verbert et al. (2014) reviewed in their research, various types of data can be collected and visualized which are relevant with learners' behaviors, including learners' social interaction with other learners or systems, resource use which is used in examples of recommender systems, to estimate learners' knowledge levels, time spent which is visualized for instructors and learners to help them understand learners' time and efforts spent on specific learning sessions, and also the test and self-assessment results that capture knowledge and self-awareness levels.

Kim et al. (2016) examined the effects of a learning analytics dashboard, which presents students with frequency data of certain activities in a college online course. As the results indicate, students who receive a dashboard treatment achieve a higher final score than those who do not; however, the dashboard usage frequency does not have a significant impact on the learning achievement.

Roberts et al. (2017) emphasized student involvement in the dashboard development process and analyzed the students' attitudes toward learning analytic dashboards. As their results indicate, students want access to additional resources easily or general links to an assessment or unit, numerical (class mean $/$ median $/ \mathrm{max} / \mathrm{min}$ ) or graphical statistics, and an anonymous comparison with their peers, among other information.

Based on a review of previous studies, and taking the good features pointed out above into account, we designed a dashboard to support learners' KM, learning process monitoring, and regulation during SRL.

\section{DESIGN OF LA DASHBOARD FOR METACOGNITION}

Our learning-analytics based dashboard consists of two parts: knowledge monitoring and use strategies. In the use strategy phase, three dimensions, namely, planning, monitoring, and regulating, are included.

The learning analytics dashboard was designed based on the BookRoll system (see Figure 1), and the data collection is conducted using this system. BookRoll is an e-book system applied to distribute digital versions of course materials. Students can highlight the contents or add annotations within the digital materials. Furthermore, the accumulated data on the students' use of the BookRoll system functions can be collected and used to visually represent their processes in viewing the materials (Ogata et al., 2017). 


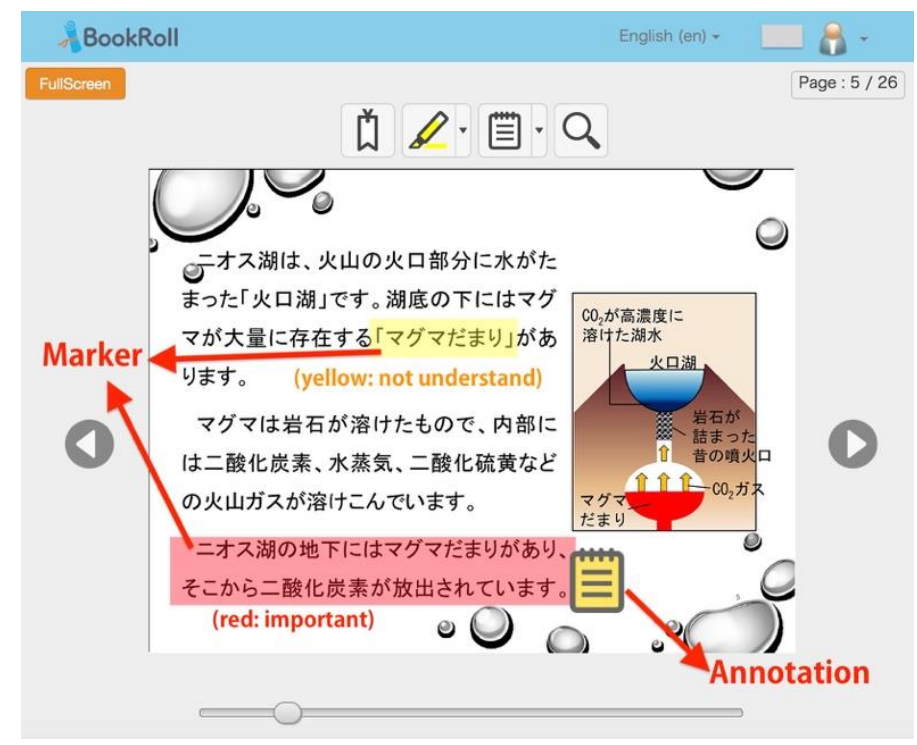

Figure 1. Interface of BookRoll system

\subsection{Knowledge Monitoring}

Based on the "hierarchy of metacognitive processes" proposed by Tobias and Everson (2009), in which knowledge monitoring is placed in the fundamental phase of the metacognitive processes, one component of our dashboard is to support the knowledge monitoring of learners.

With metacognitive skills used to monitor one's own prior knowledge, learners can adopt more appropriate learning strategies. For example, they can decide to skip parts of the learning materials that they are familiar with or have already mastered or focus on the parts they do not yet understand and seek help from others based on their recognition that their knowledge needs to be improved or supplemented (Tobias and Everson, 2009). Thus, in our study, we designed a dashboard to support learners in knowledge acquisition by providing them access to recommended learning materials related to the knowledge they do not know or are not familiar with.

To assess the monitoring of prior knowledge of the learners, Tobias and Everson (2002) developed a knowledge monitoring assessment (KMA). With KMA, learners are required to estimate whether they can solve each problem, and then take a test on the same content; the accuracy of KM of the learners can be inferred through a comparison of the accuracy between the metacognitive estimation and their test performance.

In addition, using a KMA, the knowledge monitoring of the learners can be divided into four types: (1) estimated as known and with a correct answer on the test $(++),(2)$ estimated as known but with an incorrect answer on the test (+ -), (3) estimated as unknown but with a correct answer (- +$)$, and (4) estimated as unknown and with an incorrect answer (- -) (Tobias and Everson, 2002).

The first $(++)$ and fourth (- -) types of learners show consistency between their KM and the actual knowledge acquisition, whereas there is a difference in that the fourth type needs greater effort in the learning content and knowledge. By contrast, the second $(+-)$ and third $(-+)$ types of learners show a discrepancy in estimating and utilizing their knowledge and indicate an insufficient KM skill of metacognition. On our designed dashboard, the estimation and actual results of the tests, as well as the pattern of the KM, are presented to learners, who are divided into one of four KM categories according to the most frequent pattern they demonstrate. All of these categories are presented to the learners through a graph, with the test scores shown along the x-axis, and the numbers of their "correct" and "incorrect" judgements shown along the y-axis.

In Figure 2, the design of the "knowledge monitoring dashboard" is shown. On this dashboard, the results of the tests and their knowledge estimation, as well as the KM pattern according to such data, are provided to learners. For learners who have difficulties in knowledge acquisition, the link between the contents they do 
not understand with the related digital learning materials will also be provided. When learners make a mistake on the test, the "link to the related materials" icon is presented next to the answer. In addition, when they click the icon, learners can access the recommended materials on the BookRoll system through the link.

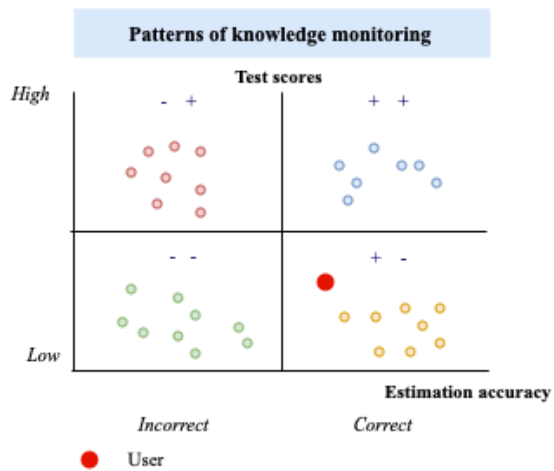

Figure 2. Design of knowledge monitoring dashboard

\subsection{Planning}

As we reviewed in the theoretical background section, the aim of planning is the development of cognitive strategies through activities such as organizing the contents and activating prior knowledge (Hofer et al., 1998). In our study, we considered designing our dashboard in a way that does not support the planning process, but applies a preplanning phase to help learners organize their learning content and compared it with that of other learners.

Thiede and Anderson (2003) proposed that, after reading a text, it is effective to improve the learner's understanding and comprehension by summarizing the contents using keywords and then rereading the text that the learner is unfamiliar with. Considering the effectiveness of a summarization approach, we designed the dashboard to support the metacognition of knowledge organization by showing learners how to utilize BR-Map.

BR-Map is a concept map tool using logs stored on the BookRoll system (see Figure 3). BR-Map can read and list all logs of highlights and annotations from the BookRoll database (the operations applied when learners read e-learning materials) and display them as objects on the left-side pane. Learners click an object on the left-side pane, and drag-and-drop it into the right-side pane, namely, the "concept map area," and create concept map(s) by connecting the objects using an "arrow" (Yamada et al., 2018).

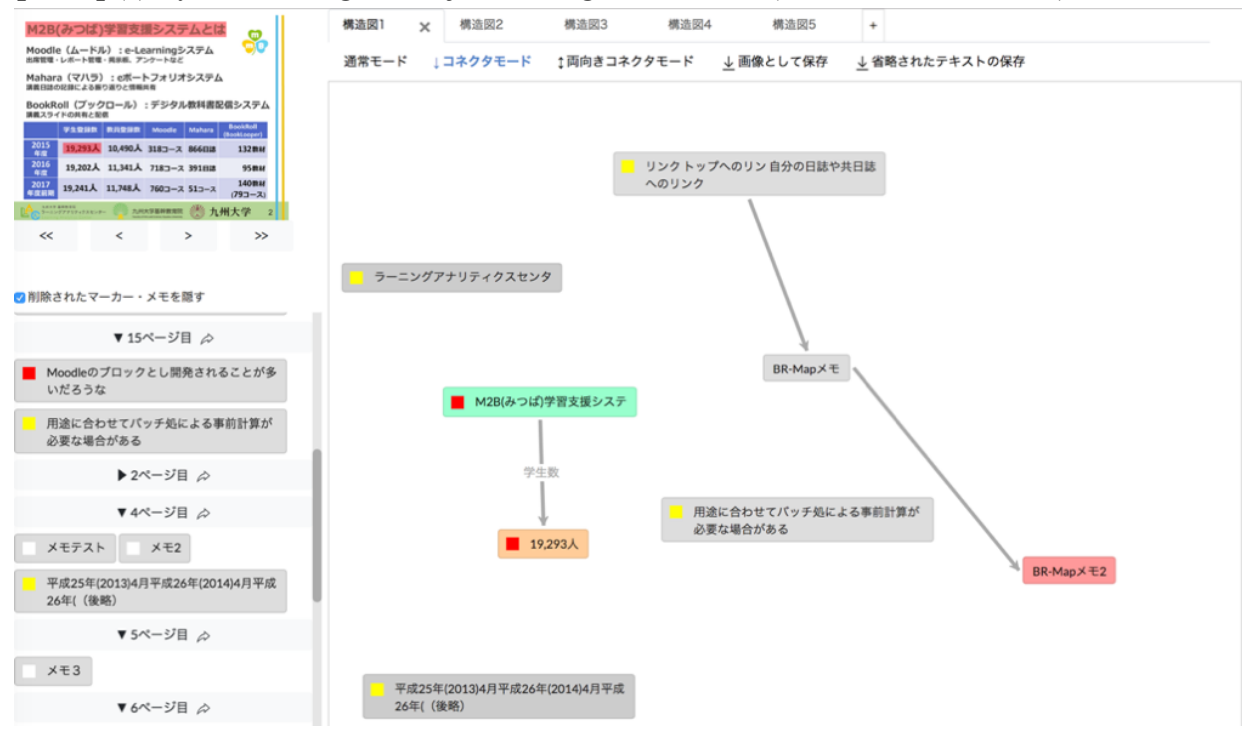

Figure 3. Interface of BR-Map 
With our dashboard, to improve the learner's perception of the knowledge organization and construction, we designed a function for presenting the slide pages applied when making the user's own BR-Map, or for adding highlights or annotations to these pages; the details of BR-Map of the learner or other students are presented when clicking on the slide pages icon (Figure 4).

\subsection{Monitoring and Regulation}

Monitoring strategies alert learners to concentrate on and understand their learning processes to regulate learning. During the monitoring phase, learners are expected to focus on the processes rather than the outcome only (Zimmerman, 1998). Many activities can be conducted to support self-monitoring, such as tracking the learner's attention to the learning materials, determining how well the learner reads a text, or checking for the learner's understanding of a particular lecture.

Therefore, in our design, how learners read a learning text, and the time they spend on each page, is shown on the dashboard (in Figure 4). A thicker arrow means more learners are reading on the same path, and the intensity of the color indicates the time they spend on each page; the darker the color, the more time the learners required.

Because the point of a self-evaluation is a comparison of one's own performance or behaviors based on certain criteria or standards (Belfiore and Hornyak, 1998), it is necessary to provide learners with the criteria or standards to make a judgement regarding whether they finished the work well. However, it is difficult to generate standard learning behaviors, and considering the class average information and an anonymous comparison to the learner's peers, which is information sought out by students, we provide both the individual utilization of BookRoll system tools, and a class average utilization. Learners can switch the frame by clicking the "Me" and "Class" icons.

In addition, when learners click the slide page, the detailed information will be provided on the dashboard, including the numbers and contents of the markers (highlighting), the numbers of annotations, and the time they spent on each page (Figure 5). By checking the information of the learning materials and comparing the information with other students, learners are expected to become aware of their insufficient understanding of the materials, as well as the contents they should concentrate on, and thus finally improve their selection of cognitive strategies and learning behaviors.

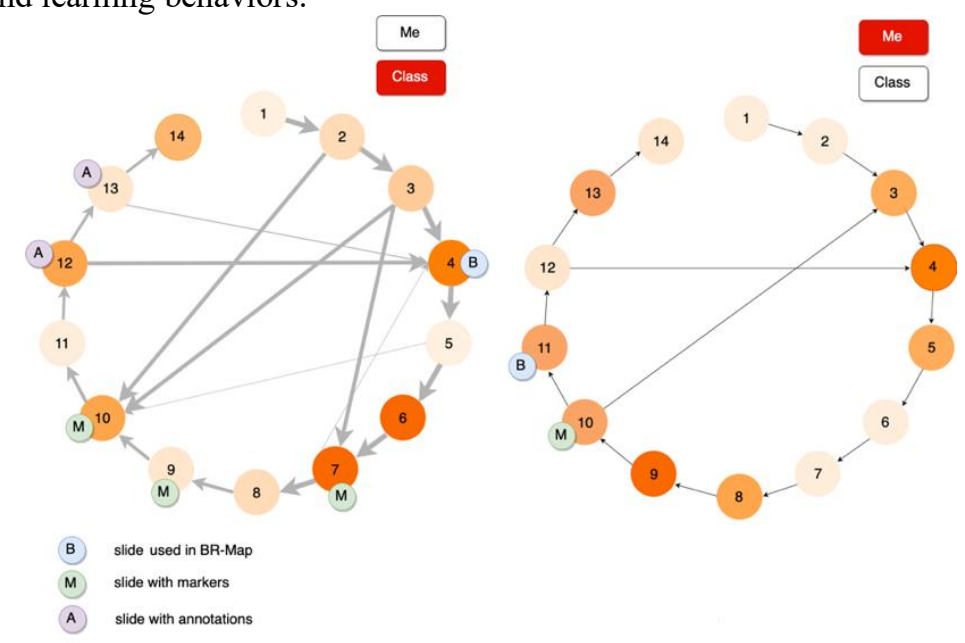

Figure 4. Design of strategy using dashboard 1 - slide reading path and time 


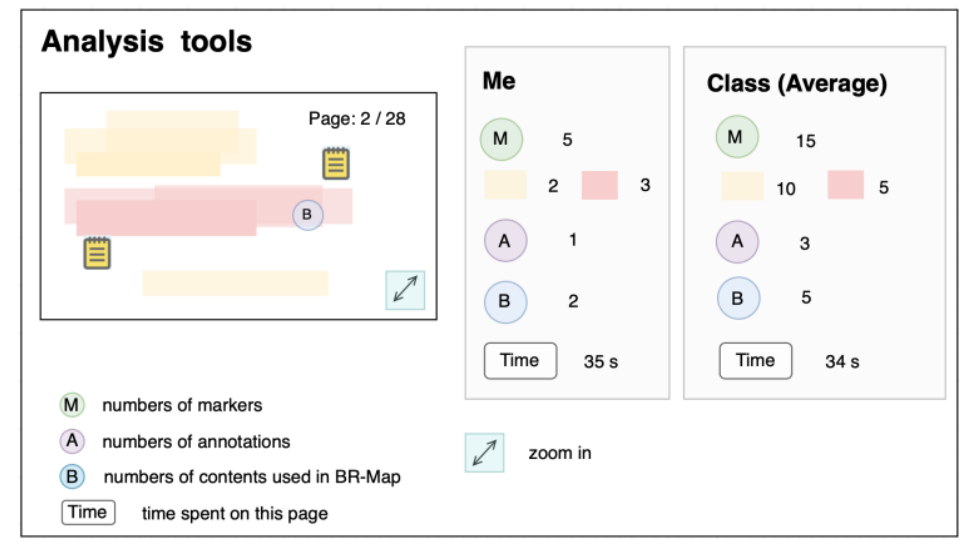

Figure 5. Design of strategy using dashboard 2 - analysis tools

\section{CONCLUSION AND FUTURE STUDIES}

In the present study, we designed a learning analytics dashboard to support the metacognition of learners regarding the dimensions of knowledge, planning, monitoring, and regulation. However, we have yet to develop this dashboard fully, and we were unable to clarify whether it achieves the expected level of effectiveness. Therefore, in a future study, we will develop this dashboard further and evaluate the dashboard especially in the dimension of effectiveness, efficiency, usefulness, and usability (Verbert et al. 2014) through a practical experiment.

\section{ACKNOWLEDGEMENT}

This work was supported by a JST AIP, Grant No. JPMJCR19U1, Japan.

\section{REFERENCES}

Belfiore, P. J. and Hornyak, R. S., 1998. Operant theory and application to self-monitoring in adolescents. In: Schunk, D. H., and Zimmerman, B. J. (eds.), Self-Regulated Learning: From Teaching to Self-Reflective Practice, Guilford Press, New York.

Hofer, B. et al., 1998. Teaching college students to be self-regulated learners. In: Schunk, D. H., and Zimmerman, B. J. (eds.), Self-Regulated Learning: From Teaching to Self-Reflective Practice, Guilford Press, New York.

Kim, J. et al, 2016. Effects of Learning Analytics Dashboard: Analyzing the Relations among Dashboard Utilization, Satisfaction, and Learning Achievement, Asia Pacific Education Review, Vol. 17, No. 1, pp. 13-24.

Lan, W, Y., 1998. Teaching self-monitoring skills in statistics. In: Schunk, D. H., and Zimmerman, B. J. (eds.), Self-Regulated Learning: From Teaching to Self-Reflective Practice, Guilford Press, New York.

Manlove, S. et al, 2006. Regulative Support for Collaborative Scientific Inquiry Learning, Journal of Computer Assisted Learning, Vol. 22, No. 2, pp. 87-98.

Ogata, H. et al, 2017. M2B System: A Digital Learning Platform for Traditional Classrooms in University. Practitioner Track Proceedings of the Seventh International Learning Analytics \& Knowledge Conference (LAK 2017). Paper presented at Simon Fraser University, Vancouver, Canada, pp. 155-162.

Pintrich, P. R. et al, 1993. Reliability and Predictive Validity of the Motivated Strategies for Learning Questionnaire (MSLQ), Educational and Psychological Measurement, Vol. 53, No. 3, pp. 801-813.

Pintrich, P. R., 1999. The Role of Motivation in Promoting and Sustaining Self - Regulated Learning, International Journal of Educational Research, Vol. 31, No. 6, pp. 459-470. 
Roberts, L. D. et al, 2017. Give Me a Customizable Dashboard: Personalized Learning Analytics Dashboards in Higher Education, Technology, Knowledge and Learning, Vol. 22, No. 3, pp. 317-333.

Shimada, A. et al, 2015. Informal learning behavior analysis using action logs and slide features in e-textbooks, Proceedings of IEEE ICALT 2015, pp.116-117.

Teasley, S. D., 2017. Student Facing Dashboards: One Size Fits All? Technology, Knowledge and Learning, Vol. 22, No. 3, pp. 377-384.

Thiede, K. W. et al., 2009. Metacognitive monitoring during and after reading. In: Handbook of Metacognition in Education, Routledge.

Thiede, K. W. and Anderson, M. C., 2003. Summarizing Can Improve Metacomprehension Accuracy. Contemporary Educational Psychology, Vol. 28, No. 2, pp. 129-160.

Tobias, S. and Everson, H. T., 2002. Knowing What You Know and What You Don't: Further Research on Metacognitive Knowledge Monitoring, Research Report No. 2002-3. College Entrance Examination Board.

Tobias, S. and Everson, H. T., 2009. The importance of knowing what you know: A knowledge monitoring framework for studying metacognition in education. In: Handbook of Metacognition in Education, Routledge.

Verbert, K. et al, 2014. Learning dashboards: an overview and future research opportunities. Personal and Ubiquitous Computing, Vol. 18, No. 6, pp. 1499-1514.

Winne, P. H. and Nesbit, J. C., 2009. Supporting Self-Regulated Learning with Cognitive Tools. In: Handbook of Metacognition in Education, Routledge.

Winne, P. H. and Stockley, D. B., 1998. Computing technologies as sites for developing self-regulated learning. In: Schunk, D. H., and Zimmerman, B. J. (eds.), Self-Regulated Learning: From Teaching to Self-Reflective Practice, Guilford Press, New York.

Yamada, M. et al, 2016. Learning Analytics in Ubiquitous Learning Environments: Self-Regulated Learning Perspective. Proceedings of International Conference on Computers in Education 2016 (ICCE 2016), pp. 306-314.

Yamada, M. et al, 2018. BR-MAP: Concept Map System using e-Book Logs. In 15th International Conference on Cognition and Exploratory Learning in the Digital Age (CELDA 2018), pp. 248-254.

Yamada, M. et al, 2017. Learning Analytics of the Relationships among Self-Regulated Learning, Learning Behaviors, and Learning Performance, Research and Practice in Technology Enhanced Learning, Vol. 12, No. 1, p. 13.

Yen, M. H. et al, 2018. Assessing Metacognitive Components in Self-Regulated Reading of Science Texts in E-Based Environments, International Journal of Science and Mathematics Education, Vol. 16, No. 5, pp. 797-816.

Yen, M. H. et al, 2018(b). A Framework for Self-Regulated Digital Learning (SRDL), Journal of Computer Assisted Learning, Vol. 34, No. 5, pp. 580-589.

Yin, C. et al, 2015. Analyzing the Features of Learning Behaviors of Students using e-Books, Proceedings of International Conference on Computers in Education 2015 (ICCE 2015), pp.617-626

Zhang, M. L. and Quintana, C., 2012. Scaffolding Strategies for Supporting Middle School Students' Online Inquiry Processes, Computers \& Education, Vol. 58, No. 1, pp. 181-196.

Zimmerman, B. J., 1998. Developing self-fulfilling cycles of academic regulation: An analysis of exemplary instructional models. In: Schunk, D. H., and Zimmerman, B. J. (eds.), Self-Regulated Learning: From Teaching to Self-Reflective Practice, Guilford Press, New York.

Zimmerman, B. J., 1989. A social cognitive view of self-regulated academic learning, Journal of Educational Psychology, Vol. 81, No. 3, 329.

Zimmerman, B. J., 2002. Becoming a Self-Regulated Learner: An Overview, Theory into Practice, Vol. 41, No. 2, 64-70. 